\title{
Mobile Multimodal Learning Analytics Method to Foster Student Self-Regulated Learning
}

\author{
Mohammad Khalil \\ Centre for the Science of Learning \& Technology (SLATE), University of Bergen \\ mohammad.khalil@uib.no \\ Olga Viberg \\ KTH Royal Institute of Technology \\ oviberg@kth.se
}

\begin{abstract}
The aim of this workshop paper is to propose Mobile Multimodal Learning Analytics Methodology (MOLAM). The methodology is suggested to be developed through the lenses of multidisciplinary and multichannel data research approaches, based on the theoretical foundations of Self-Regulated Learning (SRL). MOLAM is theory supported, driven by learning analytics, learner-centered focused, and mobile technology utilized. We argue that MOLAM will have a potential to support learners, teachers and researchers in their understanding and their further fostering of student SRL in formal and informal learning environments.
\end{abstract}

Keywords: Learning analytics; mobile multimodal learning analytics methodology; multichannel data; self-regulated learning

\section{BACKGROUND AND METHOD PROPOSAL}

The aim of this workshop paper is to discuss our proposal of a research area which we call Mobile Multimodal Learning Analytics Methodology (MOLAM) to trace, interpret and support students' development of self-regulated learning (SRL) strategies, skills and knowledge. While the focus of the learning analytics research varies (Khalil \& Ebner, 2016; Viberg et al., 2018), increasing research attempts have recently targeted the area of self-regulated learning (SRL; Viberg, Khalil \& Baars, 2020).

SRL refers to how learners steer their own learning (Wong et al., 2019). It is a broad processoriented concept that encompasses motivational, metacognitive, cognitive, affective, and behavioural aspects of learning (Panadero, 2017). It is a well researched area. Yet, related research attempts have largely focused on understanding SRL activities as static learning processes by using subjective self-reported assessment measures such as surveys, self-reported or think-aloud methods. However, SRL is not only a static process; it increasingly evolves (Sedryakyan et al., 2018), and even though considerable theoretical and conceptual progress has been made with respect to regulation in learning, there has been "little progress in developing methods to make the primary invisible mental regulation processes [...] visible and thus measurable and ultimately interpretable" (Noroozi et al., 2019, p. 299). This is critical since earlier research has shown that many students possess poor SRL practices, including the ability to accurately calibrate their own learning processes (Dunlosky \& Rawson, 2007). Further, it has been found that without instructional support, students 
may overestimate their understanding of learning materials (Baars et al., 2018; Thiede et al., 2009). All this suggests that to be able to successfully support learners in their development of SRL, we need to better understand the evolving continuous nature of the multifaceted learning processes that constitute their SRL. To fill this gap, we propose the innovative MOLAM that is argued to benefit from the use of mobile learning analytics (Aljohani \& Davis, 2012) in a combination with multimodal data collection, the analysis of which has earlier been found beneficial for the understanding of students' SRL processes (Järvelä et al., 2019).

MOLAM will be developed based on the theoretical grounding of SRL (e.g., Zimmerman, 1990; Zimmerman \& Schunk, 2011; Panadero, 2017). MOLAM brings potential in terms of generating multichannel mutually constituting process-oriented SRL data. Firstly, the use of mobile technologies in combination with learning analytics (LA) is an under-researched area within the field of LA and educational data mining (Shorfuzzaman et al., 2019). The area is challenging because of the characteristics offered by mobile devices. For example, there is a large amount of temporal processoriented learner data that can be collected with a different flavour than those existing in web-based systems. Mobile learning provides possibilities of having localized data and information collected from numerous learning sessions (Tabuenca et al., 2015) continuously occurring across formal and informal educational settings. Combined with learning analytics, or Mobile Learning Analytics (Aljohani \& Davis, 2012), it is understood as "the collection, analysis and reporting of the data of mobile learners, which can be collected from the mobile interactions between learners, mobile devices and available learning materials; it is also supported by the pre-registered data about learners in different university systems" (p. 71).

Secondly, the use of multimodal data collection together with LA is getting increased attention during the last years (e.g., Dindar et al., 2019; Järvelä et al., 2019). In mobile technologies, data, as a multimodal data source, can be generated through built-in services and sensors such as GPSlocation, wifi signals, speech input, and fingerprints. Within educational context, mobile multimodal data will offer new insights on state-of-the-art approaches for learning behaviours including metacognitive and cognitive aspects of learning which by then imply SRL processes.

Based on the fact that SRL cannot only be learnt, but also taught (Raaijmakers et al., 2018), the proposed method will aid three groups of stakeholders, namely students, teachers, and researchers. To support students in their development of SRL, we argue that they will benefit from, but not limited to, two support tools. On the one hand, they will benefit from the use of specially developed or adapted software/apps - that are easily accessible through their mobile devices (e.g., smartphones and/tablets) - aiming at explaining and practicing SRL in selected learning settings. Through the use of their own mobile technologies, in which we propose to integrate mechanisms for collecting multimodal data, a relevant process-oriented multichannel data will be collected. On the other hand, by applying mixed-methods mobile multimodal learning analytics approaches, for instance including sensors data together with fingerpress stream, the results will be used to develop a student-facing learning dashboard - a digital tool that visualises students' SRL processes, based on a multichannel data stream (including student log activity data from the adapted SRL software use and multimodal data), with the overall goal to facilitate the development of students' selfregulation. Making SRL processes continuously visible for learners will improve their ability to selfregulate their learning. 
The findings of the mobile multimodal learning analytics will also be employed to aid teachers through the development of a teacher-faced learning dashboard that will visualise students' SRL processes, both on individual- and group level. This dashboard will assist teachers not only in their understanding of students' SRL processes but also in designing and practicing relevant teaching activities aiming at further fostering students' SRL in educational settings and providing adequate support.

Finally, to aid researchers to trace and interpret students' SRL activities through a process-oriented approach, we suggest that a graphical user interface that will facilitate data visualisation and processing, thus offering new opportunities for researchers to travel through the learner data and its characteristics needs to be developed. This will contribute to a deeper understanding of the underexplored role of self-regulation in the mobile learning research field (Viberg \& Andersson, 2019) and a further theoretical development of the SRL research area.

\section{FUTURE RESEARCH DIRECTION}

At the triangle connection between learning analytics, mobile technology, and SRL could offer new methods that are not primarily based on frequently used subjective assessment measures, such as learners' perceptions and attitudes towards their SRL, but on the actual use of SRL strategies and related SRL activities during learning. Future directions should be initiated by developing mobile applications that aim at fostering student SRL in increasingly emerging online learning settings and that use multichannel data to measure and track ongoing SRL activities. MOLAM can then be utilized to provide adaptive SRL interventions that will aid teachers to support their learners. We believe unfolding a structure and a framework for MOLAM will be promising in the LA research area considering both the ethical and privacy aspects of students learning behaviour.

\section{REFERENCES}

Aljohani, N. R., \& Davis, H. C. (2012). Significance of learning analytics in enhancing the mobile and pervasive learning environments. In 2012 Sixth International Conference on Next Generation Mobile Applications, Services and Technologies (pp. 70-74). IEEE.

Baars, M., Leopold, C., \& Paas, F. 2018. Self-explaining steps in problem-solving tasks to improve self-regulation in secondary education. Journal of Educational Psychology, 110, 578-595. DOI: 10.1037/edu0000223

Dindar, M., Malmberg, J., Järvelä, S., Hataaja, E., \& Kirschner, P. (2019). Matching self-report with electrodermal activity data: Investigating temporal changes in self-regulated learning. Education and Information Technologies. DOI: 10.1007/s10639-019-10059-5

Dunlosky, J., \& Lipko, A. R. 2007. Metacomprehension a brief history and how to improve its accuracy. Current Directions in Psychological Science, 16, 228-232.

Järvelä, S., Malmberg, J., Haataja, E., Sobosincki, M. \& Kirschner, P. (2019, in press). What multimodal data can tell us about the self-regulated learning process? Learning and Instruction. DOI:10.1016/i.learninstruc.2019.04.004 
Khalil, M. \& Ebner, M. (2016). What is Learning Analytics about? A Survey of Different Methods Used in 2013-2015. In Proceedings of Smart Learning Conference, Dubai, UAE, 7-9 March, 2016 (pp. 294-304). Dubai: HBMSU Publishing House.

Noroozi, O., Alikhani, I., Järvelä, S., Kirschner, P., Seppänen, T., \& Juuso, I. (2019). Multimodal data to design visual learning analytics for understanding regulation of learning. Computers in Human Behavior. DOI: 10.1016/j.chb.2018.12.019

Panadero, E. (2017). A Review of Self-regulated Learning: Six Models and Four Directions for Research. Frontiers in Psychology, 8, 422. DOI: 10.3389/fpsyg.2017.00422

Raaijmakers, S. F., Baars, M., Schaap, L., Paas, F., Van Merriënboer, J., \& Van Gog, T. 2018. Training self-regulated learning skills with video modeling examples: Do task-selection skills transfer?. Instructional Science, 46(2), 273-290. DOI: 10.1007/s11251-017-9434-0

Shorfuzzaman, M., Hossain, M. S., Nazir, A., Muhammad, G., \& Alamri, A. (2019). Harnessing the power of big data analytics in the cloud to support learning analytics in mobile learning environment. Computers in Human Behavior, 92, 578-588.

Tabuenca, B., Kalz, M., Drachsler, H., \& Specht, M. (2015). Time will tell: The role of mobile learning analytics in self-regulated learning. Computers \& Education, 89, 53-74.

Thiede, K. W., Griffin, T. D., Wiley, J.,\& Redford, J. S. 2009. Metacognitive monitoring during and after reading. In D. J. Hacker, J. Dunlosky, \& A. C. Graesser (Eds.), Handbook of metacognition in education (pp. 85-106). New York: Routledge.

Viberg, O., \& Andersson, A. (2019). The role of self-regulation and structuration in mobile learning. International Journal of Mobile and Blended Learning. DOI: 10.4018/IJMBL.2019100104

Viberg, O., Hatakka, M., Bälter, O., \& Mavroudi, A. (2018). The current landscape of learning analytics in higher education. Computers in Human Behaviour. DOI:10.1016/j.chb.2018.07.027

Viberg, O., Khalil, M., \& Baars, M. (2020). Self-regulated learning and learning analytics in online learning environments: A review of empirical research. In proceedings of LAK'20. Frankfurt, Germany.

Wong, J., Khalil, M., Baars, M., de Koning, B. B., \& Paas, F. (2019). Exploring sequences of learner activities in relation to self-regulated learning in a massive open online course. Computers \& Education. DOI: 10.1016/j.compedu.2019.103595 